\title{
A COMPARATIVE CLINICAL EVALUATION OF THE EFFICACY OF TWO DESENSITIZING DENTIFRICES IN RELIEVING DENTINE HYPERSENSITIVITY
}

\author{
Joshi R, Gautam S, Joshi B
}

Department of Conservative Dentistry and Endodontics, College of Dental Sciences and Hospital, Attarkhel, Gokarneshwor-8, Kathmandu, Nepal

\begin{abstract}
Dentinal hypersensitivity has been defined as a short, sharp pain arising from exposed dentine in response to stimuli thermal, evaporative, tactile, chemical or osmotic and which cannot be ascribed to any other form of dental defect or pathology. This is a common clinical condition which may cause patients more distress due to exposure of dentin. There are various management options for this clinical condition which can be either home applied or in office techniques. Various dentifrices are commercially available in the market. The chemical compositions of the dentifrices are different. We conducted this study to compare the effectiveness of a potassium nitrate containing dentifrice and a Novamin based dentifrice in relieving dentinal hypersensitivity. The patients were divided into two experimental groups; group 1-potassium nitrate containing dentifrice and group 2-Novamin containing dentifrice. The sensitivity score was analyzed by using a verbal rating scale at baseline, at three weeks and at six weeks after using the dentifrices. Statistical analysis was done using SPSS version 17. Chi-square test showed that there was no significant difference between the effectiveness and efficacy of the two dentifrices. The results were highly significant $(\mathrm{p}<0.001)$. Hence, potassium nitrate and Novamin were equally effective in reducing dentinal hypersensitivity.
\end{abstract}

\section{KEYWORDS}

Dentinal hypersensitivity, potassium nitrate, Novamin

\section{CORRESPONDING AUTHOR}

Dr. Rojin Joshi

Assistant Professor,

Department of Conservative Dentistry and Endodontics,

College of Dental Sciences and Hospital,

Attarkhel, Gokarneshwor-8, Kathmandu, Nepal,

Email: rozinjoshi@yahoo.com

Orcid ID: 0000-0003-3914-3837

DOI: https://doi.org/10.3126/nmcj.v22i1-2.30030 


\section{INTRODUCTION}

Dentinal hypersensitivity has been defined as a short, sharp pain arising from exposed dentine in response to stimuli thermal, evaporative, tactile, chemical or osmotic and which cannot be ascribed to any other form of dental defect or pathology. ${ }^{1}$

Dentinal hypersensitivity can manifest if dentine is exposed by loss of enamel (due to abrasion, erosion or attrition), keeping the tubules open on the dentine surface. The constant action of acids or loss of tooth structure such as cementum denudes the root surface, which is prone to removal by brushing or periodontal treatment or more commonly, by the association of two or more of these factors. ${ }^{2-3}$ The etiology of dentinal hypersensitivity can also be caused by many alternative factors such as chipped or fractured teeth, cracked cusps, carious lesions, leaky restorations. ${ }^{4}$ Braennstroem and Astroem in 1964 proposed the 'hydrodynamic theory which is widely accepted as the explanation of the pain caused by Dentinal hypersensitivity. ${ }^{5}$ This theory states that stimulus transmission is due to the rapid shift of fluid movement in either direction within the dentinal tubules stimulating mechanoreceptors in or near the pulp. Increased sensitivity may therefore, be due to an increase in fluid flow within the tubules. ${ }^{6}$ The incidence may affect patients of any age and reportedly peaks during the third and fourth decades of life. ${ }^{7}$

Sensitivity to thermal stimulus - heat and cold is the most prevalent complaint by hypersensitive individuals. In general, the incidence of hypersensitive dentin ranges from $10 \%$ to $30 \%$ of the population. ${ }^{8}$

A wide variety of treatment options are available for the management of dentinal hypersensitivity. The treatment options are the application of chemicals such as stannous fluoride, sodium fluoride, copal varnishes, potassium oxalates, potassium nitrates, desensitizing agents and fluoride treatment with or without iontophoresis.

Home applied agents like mouthwashes and dentifrices are effective in reducing dentinal hypersensitivity. The effects of home-applied agents are manifested after a period of time and also require patient compliance. ${ }^{9}$ Studies have shown that topical application of sodium fluoride is effective. ${ }^{10}$ Studies have shown that Novamin powder with Novamin containing toothpaste have shown significant reduction in hypersensitivity. ${ }^{11}$ NovaMin is a biocompatible bioactive glass. It has been used for treating dentinal hypersensitivity and occludes the open tubules by depositing hydroxycarbonate apatite (HCA), a mineral that is chemically and structurally similar to the mineral present in dentin and enamel. ${ }^{12}$ Dentifrices containing potassium nitrate are easily available and preferred oral health care products. Potassium ions are thought to act by blocking the action potential generated in intradental nerves. ${ }^{13}$

\section{MATERIALS AND METHODS}

This comparative cross sectional study was conducted amongst patients who had visited the Department of Conservative Dentistry and Endodontics Attarkhel, Gokarneshwor-8, Kathmandu with a complain of hypersensitivity. We conducted this study after obtaining ethical approval from Nepal Medical College Institutional Review Committee (NMC-IRC reference number 001-075/076). The total duration of study was six weeks. All the participants received a detailed explanation regarding the study procedure, and written informed consent was obtained from the patients. Confidentiality and anonymity of the study respondents was assured and maintained. Patients who had a history of tooth hypersensitivity to thermal, sweet, mechanical or sour stimuli on at least one tooth, those who were willing to participate in the study for 6 weeks with good physical and overall health were included. Patients excluded from the study were patients having defective restoration, cracked tooth syndrome, faulty restorations, deep periodontal pockets and chipped tooth, those who were undergoing orthodontic treatment and with prosthodontic appliances and who have already undergone treatment for tooth hypersensitivity.

The hypersensitive teeth were identified. The affected teeth of the patients were evaluated using three different stimuli. The stimuli used were tactile test, airblast test and cold water. They were evaluated in the following way.

1. Tactile test. A sharp dental explorer was passed over affected tooth, perpendicular to the long axis of the tooth. The score was noted using the discomfort scale.

2. Air blast test. A blast of air from a 3-way dental syringe was directed on affected area of the tooth for 1 second from a distance of $10 \mathrm{~mm}$. Adjacent teeth were protected with cotton rolls.

3. Cold water test. A $1 \mathrm{ml}$ disposable syringe was filled with ice cold water. After isolating the particular tooth, $0.2 \mathrm{ml}$ of the water was slowly expelled from the syringe onto the tooth surface.

For all stimuli tests, patient's responses were recorded on the following verbal rating scale (VRS).${ }^{11}$ The patients with a verbal rating scale score of 2 or more were included in the study. 


$$
\begin{aligned}
& 0=\begin{array}{l}
\text { no significant discomfort, or awareness } \\
\text { of stimulus. }
\end{array} \\
& 1=\text { discomfort, but no severe pain. } \\
& 2=\begin{array}{l}
\text { severe pain during application of } \\
\text { stimulus. }
\end{array} \\
& 3=\begin{array}{l}
\text { severe pain during and after application } \\
\text { of stimulus. }
\end{array}
\end{aligned}
$$

The patients were divided into two experimental groups and were given two different dentifrices: group 1-Potasium nitrate containing dentifrice, group 2-Novamin containing dentifrice. They were instructed to use the dentifrice twice a day. The patients were evaluated three times during the six week period of study. The teeth were evaluated at baseline at 0 days, at three weeks and at the end of six weeks using the three stimuli tests at an interval of 5 minutes in between different stimuli. A total of 96 patients in each group (total of 192) participated in the study with a dropout rate of $15 \%$. Hence, 82 patients (total of 164) in each group completed the study. The data was entered, edited and coded in Microsoft
Excel version 7.0. The data was exported and analyzed with the help of Statistical Package for Social Sciences (SPSS) version 17. The descriptive statistics like mean, median, standard deviation were calculated. The data was statistically analyzed using chi square test.

\section{RESULTS}

A total of 164 patients participated in this study. There were 82 patients in each group (group 1 and group 2)

Group 1: When assessed at baseline, 3 weeks and 6 weeks with three different stimuli tactile, air and cold stimulus. The mean values of verbal rating scale were .93( \pm .766 SD), .59( \pm .587$), .15( \pm .356)$ at baseline 3 weeks and 6 weeks for tactile stimulus, 1.46 ( \pm .613$), 0.87( \pm .662), 0.30( \pm .463)$ at baseline 3 weeks and 6 weeks for air stimulus and 1.76

\begin{tabular}{|c|c|c|c|c|c|c|c|}
\hline Type of stimuli & Time interval & $\mathbf{N}$ & Mean & S.D. & Chi square & Sig. & Inference \\
\hline \multirow{4}{*}{ Tactile } & Baseline & 82 & 0.80 & 0.693 & \multirow{3}{*}{81.430} & \multirow{3}{*}{$0.000(<<0.001)$} & \multirow{3}{*}{ Significant } \\
\hline & Week 3 & 82 & 0.55 & 0.612 & & & \\
\hline & Week 6 & 82 & 0.09 & 0.281 & & & \\
\hline & Baseline & 82 & 1.40 & 0.626 & \multirow{3}{*}{123.798} & \multirow{3}{*}{$0.000(<<0.001)$} & \multirow{3}{*}{ Significant } \\
\hline \multirow[t]{2}{*}{ Air } & Week 3 & 82 & 0.82 & 0.687 & & & \\
\hline & Week 6 & 82 & 0.18 & 0.389 & & & \\
\hline \multirow{3}{*}{ Cold } & Baseline & 82 & 1.62 & 0.536 & \multirow{3}{*}{126.241} & \multirow{3}{*}{$0.000(<<0.001)$} & \multirow{3}{*}{ Significant } \\
\hline & Week 3 & 82 & 1.10 & 0.678 & & & \\
\hline & Week 6 & 82 & 0.38 & 0.536 & & & \\
\hline
\end{tabular}
( \pm .460$), 1.33( \pm .610), 0.62( \pm .536)$ at baseline 3 weeks and 6 weeks for cold stimulus respectively (Table 1).

\begin{tabular}{|lccccccc|}
\hline & \multicolumn{7}{c|}{ Table 1: Group 1 } \\
Type of stimuli & Time interval & $\mathbf{N}$ & Mean & S.D. & Chi square & Sig. & Inference \\
\hline \multirow{3}{*}{ Tactile } & Baseline & 82 & 0.93 & 0.766 & & & \\
& Week 3 & 82 & 0.59 & 0.587 & 81.593 & $0.000(<<0.001)$ & Significant \\
& Week 6 & 82 & 0.15 & 0.356 & & & \\
Air & Baseline & 82 & 1.46 & 0.613 & & & \\
& Week 3 & 82 & 0.87 & 0.662 & 118.506 & $0.000(<<0.001)$ & Significant \\
& Week 6 & 82 & 0.30 & 0.463 & & & \\
Cold & Baseline & 82 & 1.76 & 0.460 & & & \\
& Week 3 & 82 & 1.33 & 0.610 & 122.820 & $0.000(<<0.001)$ & Significant \\
\hline
\end{tabular}


Group 2: When assessed at baseline, 3 weeks and 6 weeks with three different stimuli tactile, air and cold stimulus. The mean values of verbal rating scale were $0.80( \pm .639), 0.55( \pm .612), 0.09( \pm .281)$ at baseline 3 weeks and 6 weeks, for tactile stimulus, $1.40( \pm .626), 0.82( \pm .687), 0.18( \pm .389)$ at baseline 3 weeks and 6 weeks for air stimulus, 1.62 ( \pm .536$)$, $1.10( \pm .678), 0.38( \pm .536)$ at baseline 3 weeks and 6 weeks for cold stimulus respectively (Table 2).

Group 3: When two different groups were compared. In tactile test from baseline to 3 weeks the response of group $1(p=0.021)$ verbal rating scale was significantly better than group 2 $(p=0.095)$, which indicated greater improvement of potassium nitrate over Novamin paste from baseline to 3 weeks. When the results of the two groups were compared, there were no significant differences in any of three stimuli. The results were highly significant $(p<0.001)$ for all three stimuli test at the different time intervals. Hence, both the dentifrices were equally effective (Table 3 ).
Potassium nitrate doesn't promote obstruction of dentinal tubules by the deposition of crystals. According to Wilchgers and Ermert ${ }^{16}$ and Kim et $a l,{ }^{17}$ the desensitizing effect of potassium nitrate is due to the increase in concentration of extracellular potassium around the nerve fibres which cause their depolarization, avoids repolarization and blocks the axonic action.This blocks the passage of nerve stimulus, resulting in inactivation of the action potential. Potassium ions are thought to act by blocking the action potential generated in intradental nerves.

The results of our study showed that both desensitizing toothpastes were equally effective in reducing dentinal hypersensitivity within six week period of evaluation. This shows that a certain period of time is necessary for the dentifrices to act. The mechanism of action of the two dentifrices were different but both of them have been equally effective in reducing dentinal hypersensitivity.

\section{Table 3: Group 3}

Group 1

Type of stimuli Time interval

\begin{tabular}{|llllll|}
\hline \multirow{3}{*}{ Tactile } & Baseline-Week 3 & 0.421 & 0.021 & 0.335 & 0.095 \\
& Baseline-Week 6 & 0.998 & 0.000 & 0.963 & 0.000 \\
& Week 3-Week 6 & 0.567 & 0.007 & 0.628 & 0.000 \\
Air & Baseline-Week 3 & 0.713 & 0.000 & 0.689 & 0.000 \\
& Baseline-Week 6 & 1.445 & 0.000 & 1.506 & 0.000 \\
\multirow{2}{*}{ Cold } & Week 3-Week 6 & 0.732 & 0.000 & 0.817 & 0.000 \\
& Baseline-Week 3 & 0.518 & 0.000 & 0.604 & 0.000 \\
& Baseline-Week 6 & 1.457 & 0.000 & 1.518 & 0.000 \\
\hline
\end{tabular}

$\mathrm{p}<<0.001$ which is statistically significant

\section{DISCUSSION}

In this study, the efficacy of two different desensitising dentifrice formulations has been compared. The two dentifrices that have been used are different in terms of chemical composition and mechanism of action. Novamin decreases dentinal hypersensitivity by occluding the open tubules. ${ }^{14}$ Novamin adheres to an exposed dentin surface and reacts with it to form a mineralized layer. The continuous release of calcium over time is suggested to maintain the protective effects on dentin, and provide continual occlusion of the dentinal tubules. ${ }^{15}$
Despite the large number of published studies, there is still no consensus on as to which product is the "gold standard" for dentin hypersensitivity treatment. ${ }^{18-19}$ Although the verbal rating scores from baseline to 3 weeks was better for potassium nitrate dentifrice compared to Novamin. The results were highly significant from baseline to six weeks for both the dentifrices on tactile, air and cold stimuli.

Mason et $a l^{20}$ concluded that there were no significant changes from baseline in tactile sensitivity for Novamin, the results were consistant with our study. Orchardson et al, ${ }^{21}$ Sharma et $a l^{10}$ have proven that potassium containing dentifrices produced a significant 
reduction in sensitivity to tactile and air stimuli. Cuesta et $a l^{22}$ have stated that there was a rapid reduction in hypersensitivity on evaporative stimulus after the first four days of application of potassium nitrate dentifrice.

Salien et $a l,{ }^{6}$ Satyapal et $a l,,^{23}$ Pradeep et $a l^{24}$ concluded that dentifrice containing 5\% NovaMin provides rapid and more relief from dentin hypersensitivity in four weeks compared to a dentifrice containing $5 \%$ potassium nitrate. This may be due to the tubule occluding property of Novamin.

On contrary to the above mentioned studies there was a significant reduction of hypersensitivity from baseline to three weeks and six weeks on tactile, air and cold stimulus in our study. Acharya et $a l^{25}$ stated that Novamin and potassium nitrate based dentifrices are equally effective in reducing dentinal hypersensitivity over a period of time. The results were similar to our study. The decrease in pain sensation to a certain extent might occur immediately after initiation of the therapy after a period of time, fluctuation of symptoms might be present due to different environmental conditions. In clinical studies, participation of the patient the answers of politeness and experimental subordination could make individuals report less pain. ${ }^{26}$ The American Dental Association Council on Dental Therapeutics has granted its Seal of Acceptance to dentifrices containing $5 \%$ potassium nitrate (Council on Dental Therapeutics 1986). ${ }^{27}$

Hence, The results of this study showed that both potassium nitrate containing dentifrice and Novamin based dentifrice showed a significant reduction in hypersensitivity over a period of six weeks from baseline on application of tactile, air and cold stimulus. Potassium nitrate showed a marked reduction of sensitivity from baseline to three weeks on tactile stimulus compared to Novamin. Hence, both the dentifrices are equally effective.

\section{ACKNOWLEDGEMENTS}

We would like to acknowledge all the patients who agreed to be a part of the study. Conflict of interests: None

\section{REFERENCES}

1. Holland GR, Narhl MN, Addy et al. Guidelines for the design and conduct of clinical trials on dentine hypersensitivity. J Clin Periodontol 1997; 24: 8-13.

2. Orchardson R, Gillam DG. Managing dentin hypersensitivity. J Am Dent Assoc 2006; 137: 990-8.

3. Addy M. Tooth brushing, tooth wear and dentine hypersensitivity- are they associated. Int'l Dent J 2005; 55: 261-7.

4. Bubteina N, Garoushi S. Dentine Hypersensitivity: A Review. Dentistry 2005; 5: 2-7.

5. Braennstroem M, Astroem A. A study on the mechanism of pain elicited from the dentin. J Dent Res 1964; 43: 619-25.

6. Salian S, Thakur S, Kulkarni S, LaTorre G. A randomized controlled clinical study evaluating the efficacy of two desensitizing dentifrices. J Clin Dent 2010; 21: 82-7.

7. Rees JS, Addy M. A cross-sectional study of buccal cervical sensitivity in UK general dental practice and a summary review of prevalence studies. Int'l J Dent Hyg 2004; 2: 64-9.

8. Bartold PM. Dentinal hypersensitivity: A review. Aust Dent J 2006; 51: 212-8.

9. Purra AR, Mushtaq M, Acharya SR, Saraswati V. A comparative evaluation of propolis and $5.0 \%$ potassium nitrate as a dentine desensitizer: A clinical study. J Indian Soc Periodontol 2014; 18: 466-71.
10. Sharma S, Shetty N, Uppoor A. Evaluation of the clinical efficacy of potassium nitrate desensitizing mouthwash and a toothpaste in the treatment of dentinal hypersensitivity. J Clin Exp Dent 2012; 4: 28-33.

11. Thumar G, Mengji A, Kumar A, Devarathnamma. A comparative evaluation of $0.33 \%$ Sodium Fluoride (Iontophoresis) and Novamin Paste as a dentine desensitizer: A comparative study. J Dent Med Sci 2015; 14: 05-08.

12. Reddy GV, Surakanti RJ, Vemisetty HK, Doranala S, Hanumanpally JR, Malgikar S. Comparative assessment of effectiveness of Biomin, NovaMin, herbal, and potassium nitrate desensitizing agents in the treatment of hypersensitive teeth: A clinical study. J NTR Univ Health Sci 2019; 8: 24-8.

13. Markowitz K, Bilotto G, Kim S. Decreasing intradental nerve activity in the cat with potassium and divalent cations. Arch Oral Biol 1991; 36: 1-7.

14. Pradeep AR, Sharma A, Bajaj P et al. Comparison of efficacy of three commercially available dentrifices on dentinal hypersensitivity: a randomized clinical trial. Aust Dent J 2012; 57: 1-6.

15. Burwell A, Jennings D, Muscle D, Greenspan DC. NovaMin and dentin hypersensitivity in vitro evidence of efficacy. J Clin Dent 2010; 21: 66-71.

16. Wichgers TG, Emert RL. Dentin hypersensitivity. Oral Health 1997; 87: 56-9. 
17. Kim S. Hypersensitive teeth: Densensitization of pulpal sensory nerves. J Endod 1986; 12: 482-5.

18. Torwane NA, Hongal S, Goel P et al. Effect of Two Desensitizing Agents in Reducing Dentin Hypersensitivity: An in-vivo Comparative Clinical Trial. Clin J Diag Res 2013; 7: 2042-6.

19. Prasad K, Sohoni R, Tikare S, Yalamalli M, Rajesh G, Javali S B. Efficacy of two commercially available dentifrices in reducing dentinal hypersensitivity. Indian J Dent Res 2010; 21: 224-30.

20. Mason S, Kingston R, Shneyer L, Harding M. Clinical study to monitor dentinal hypersensitivity with episodic use of a desensitising dentifrice. $B D J$ Open 2017; 3: 1-7.

21. Orchardson R, Gillam DG. The efficacy of potassium salts as agents for treating dentin hypersensitivity. J Orofac Pain 2006; 4: 9-19.

22. Frechoso CS, Menendez M, Guisasola C, Arregui I, Tejerina JM, Sicilia A. Evaluation of the efficacy of two potassium nitrate bioadhesive gels $(5 \%$ and $10 \%)$ in the treatment of dentine hypersensitivity. A randomised clinical trial. J Clin Periodontol 2003; 30: 315-20.
23. Satyapal T, Mali R, Mali A, Patil V. Comparative evaluation of a dentifrice containing calcium sodium phosphosilicate to a dentifrice containing potassium nitrate for dentinal hypersensitivity: A clinical study. J Indian Soc Periodontol 2014; 18: 581-5.

24. Pradeep AR, Sharma A. Comparison of clinical efficacy of a dentifrice containing calcium sodium phosphosilicate to a dentifrice containing potassium nitrate and to a placebo on dentinal hypersensitivity: a randomized clinical trial. J Periodont 2010; 81: 1167-73.

25. Acharya AB, Surve SM , Thakur SL .A clinical study of the effect of calcium sodium phosphosilicate on dentin hypersensitivity. J Clin Exp Dent 2013; 5: 1822.

26. Rosing CK, Fiorini T, Liberman DN, Cavagni J. Dentine hypersensitivity: analysis of self-care products. Braz Oral Res 2009; 23: 56-63.

27. Recommendations for evaluating agents for the reduction of dentinal hypersensitivity. Ad Hoc Advisory Committee on Dentinal Hypersensitivity Council on Dental Therapeutics. J Am Dent Assoc 1986; 112: 709-10. 